Review

\title{
Chemical Structure, Property and Potential Applications of Biosurfactants Produced by Bacillus subtilis in Petroleum Recovery and Spill Mitigation
}

\author{
Jin-Feng Liu ${ }^{1,3}$, Serge Maurice Mbadinga ${ }^{1,3}$, Shi-Zhong Yang ${ }^{1,3}$, Ji-Dong Gu ${ }^{2}$ \\ and Bo-Zhong Mu ${ }^{1,3, *}$
}

1 State Key Laboratory of Bioreactor Engineering and Institute of Applied Chemistry, East China University of Science and Technology, Shanghai 200237, China;

E-Mails: 1jf@ecust.edu.cn (J.-F.L.); smmbadinga@ecust.edu.cn (S.M.M.); meor@ecust.edu.cn (S.-Z.Y.)

2 School of Biological Sciences, The University of Hong Kong, Pokfulam Road, Hong Kong, China; E-Mail: jdgu@hkucc.hku.hk

3 Shanghai Collaborative Innovation Center for Biomanufacturing Technology, Shanghai 200237, China

* Author to whom correspondence should be addressed; E-Mail: bzmu@ecust.edu.cn; Tel.: +86-21-6425-2063; Fax: +86-21-6425-2485.

Academic Editor: Xiaoke Hu

Received: 29 December 2014 / Accepted: 17 February 2015 / Published: 3 March 2015

\begin{abstract}
Lipopeptides produced by microorganisms are one of the five major classes of biosurfactants known and they have received much attention from scientific and industrial communities due to their powerful interfacial and biological activities as well as environmentally friendly characteristics. Microbially produced lipopeptides are a series of chemical structural analogues of different families and, among them, 26 families covering about 90 lipopeptide compounds have been reported in the last two decades. This paper reviews the chemical structural characteristics and molecular behaviors of surfactin, one of the representative lipopeptides of the 26 families. In particular, two novel surfactin molecules isolated from cell-free cultures of Bacillus subtilis HSO121 are presented. Surfactins exhibit strong self-assembly ability to form sphere-like micelles and larger aggregates at very low concentrations. The amphipathic and surface properties of surfactins are related to the existence of the minor polar and major hydrophobic domains in the three
\end{abstract}


3-D conformations. In addition, the application potential of surfactin in bioremediation of oil spills and oil contaminants, and microbial enhanced oil recovery are discussed.

Keywords: microbial biosurfactant; surfactin; structure and property; molecular behavior; potential applications; bioremediation; enhanced oil recovery

\section{Introduction}

Biosurfactants are a class of microbial metabolites with surface-active properties and they are capable of spontaneous assemblies at the air-water or water-oil interface and thereby reducing surface/interfacial tensions due to their hydrophilic and hydrophobic structural components. On the basis of their chemical structures, biosurfactants are divided into five major classes of lipopeptides, glycolipids, phospholipids, neutral lipids, and polymeric compounds [1]. Currently, many biosurfactant-producing microorganisms have been isolated and identified to belong to: Bacillus, Agrobacterium, Streptomyces, Pseudomonas, and Thiobacillus as producers of amino acids-containing biosurfactants; Pseudomonas, Torulopsis, Candida, Mycobacterium, Micromonospora, Rhodococcus, Arthrobacter, Mycobacterium, Corynebacterium, Mycobacterium, and Arthrobacter as producers of glycolipids; Thiobacillus, Aspergillus, Candida, Corynebacterium, Micrococcus, and Acinetobacter as producers of phospholipids and fatty acids [2].

As one of the typical representative biosurfactants with excellent interfacial and biological activity [3], lipopetides are mainly produced by Bacillus (such as Bacillus subtilis, B. licheniformis and B. polymyxa) [4], Pseudomonas [5], Streptomyces [6], Aspergillus [7], Serratia and Actinoplanes. Lipopeptides are classified as cyclic lipopeptides and linear ones based on their chemical structures [8]. Cyclic lipopeptides refer to those with molecular structure containing a cyclic component formed with carboxyl group in the $C$-terminal of peptide chain bonded to the amino group from the peptide chain or a hydroxyl group from fatty acid chain. Whereas, linear lipopeptides contain a linear amino acid group connected one-by-one and the fatty acid bonded to the $\alpha$-amino group or other hydroxyl group. Currently, about 90 lipopeptide compounds in 26 families have been identified and most of them were summarized previously by Liu et al. [8]. The majority of these lipopeptides belong to the cyclic ones (86 compounds in 24 families), and only four compounds in two families belong to linear ones. Among the 26 families, surfactin [9], lichenysin [10], iturin [11] and fengycin [12] are mostly investigated, of which surfactin is reported so far as the strongest biosurfactant to decrease the interfacial tension of hexadecane/water from 43 to $1 \mathrm{mN} \cdot \mathrm{m}^{-1}[13,14]$ and the surface tension of water from 72 to $27 \mathrm{mN} \cdot \mathrm{m}^{-1}$ with a critical micelle concentration (CMC) of $10^{-5} \mathrm{M}[4,14,15]$.

This paper presents the primary and spatial structure, property and molecular behaviors of surfactin in aqueous solution and at the interface of oil and water, and its potential application in bioremediation of oil spills and microbial enhancement of oil recovery is also discussed. 


\section{Structure and Property}

\subsection{Structure Characterization}

Surfactin was first reported and named in 1968 by Arima et al. [9] and its chemical structure was determined by Kakinuma et al. [16]. Surfactin composed of a peptide chain formed by seven $\alpha$-amino acids bonded to a hydroxyl fatty acid by lactone bond to form a cyclic lipopeptide. The typical sequence of amino acids in the peptide ring is: L-Glu ${ }^{1}-\mathrm{L}-\mathrm{Leu}^{2}$-D-Leu ${ }^{3}-\mathrm{L}-\mathrm{Val}^{4}-\mathrm{L}-\mathrm{Asp}^{5}$-D-Leu ${ }^{6}-\mathrm{L}-\mathrm{Leu}^{7}$ [8].

The differences in the sequence of amino acids and number of carbon atoms in the fatty acids means the surfactins contain a variety of structural analogues [8,16,17]. Baumgart et al. [18] reported that three surfactin compounds were produced by B. subtilis ATCC 21332 and OKB 105, two of which were different from the basic structure mentioned above in the amino acid Leu ${ }^{7}$ which was replaced by Val and Ile, respectively. Using the method reported by Yang et al. [19] for analysis of amino acid sequence and by Yang et al. [20] for analysis of fatty acid bonded to the peptide chain, Liu et al. [21] identified the surfactins produced by B. subtilis when incubated with the same culture medium and found three kinds of surfactins with different peptide moieties: (1) a surfactin with amino acid sequence of $N$-Asp-Leu-Leu-Val-Glu-Leu-Leu- $C$; (2) a surfactin with amino acid sequence of $N$-Glu-Leu-Leu-Val-Asp-Leu-Leu- $C$; and (3) a surfactin with the peptide chain methyl esterified. Meanwhile, the fatty acid moiety of these surfactins was identified to be diverse, including iso $\mathrm{C} 12$, iso $\mathrm{C} 13$, anteiso $\mathrm{C} 13$, iso $\mathrm{C} 14, \mathrm{n} \mathrm{C} 14$, iso $\mathrm{C} 15$, anteiso $\mathrm{C} 15, \mathrm{n} \mathrm{C} 15$, anteiso $\mathrm{C} 16$, and anteiso $\mathrm{C} 17$ beta-hydroxy fatty acids. Notably, two novel surfactin molecules were isolated and identified in our laboratory in the broth of B. subtilis HSO121. One is the C12 lipopeptide [22], which has the shortest chain length among the lipopeptides produced by $B$. subtilis. The other is the C15-surfactin-O-methyl ester [23], which is a kind of esterified lipopeptide, approved of biological origin from B. subtilis for the first time. The fatty acid portions of $\mathrm{C} 15$-surfactin- $O$-methyl ester were identified to be iso $\mathrm{C} 15$ and anteiso C15 $\beta$-hydroxy fatty acids. The peptide ring was analyzed by tandem MS as shown in Figure 1A, in which the molecular weight of 1049 was determined (deduced from the sodium ionized $\mathrm{m} / \mathrm{z}$ 1072.66) and the amino acid sequence of $N$-Glu(OMe)-Leu-Leu-Val-Asp-Leu-Leu- $C$ was identified by taking the differences of the fragment ions shown in Figure 1B (simple cleavage of intact lipopeptide) and Figure 1C,D (with double hydrogen transfer). The existence of GluOMe in the peptide ring was further supported by ${ }^{1} \mathrm{H}$ NMR (3.66 ppm indicating of the monoester of lipopeptide) and ${ }^{13} \mathrm{C}$ NMR (49.15 ppm indicating the methoxy group attached on Glu or Asp). The deduced structure of C15-surfactin- $O$-methyl ester is shown in Figure 2. 

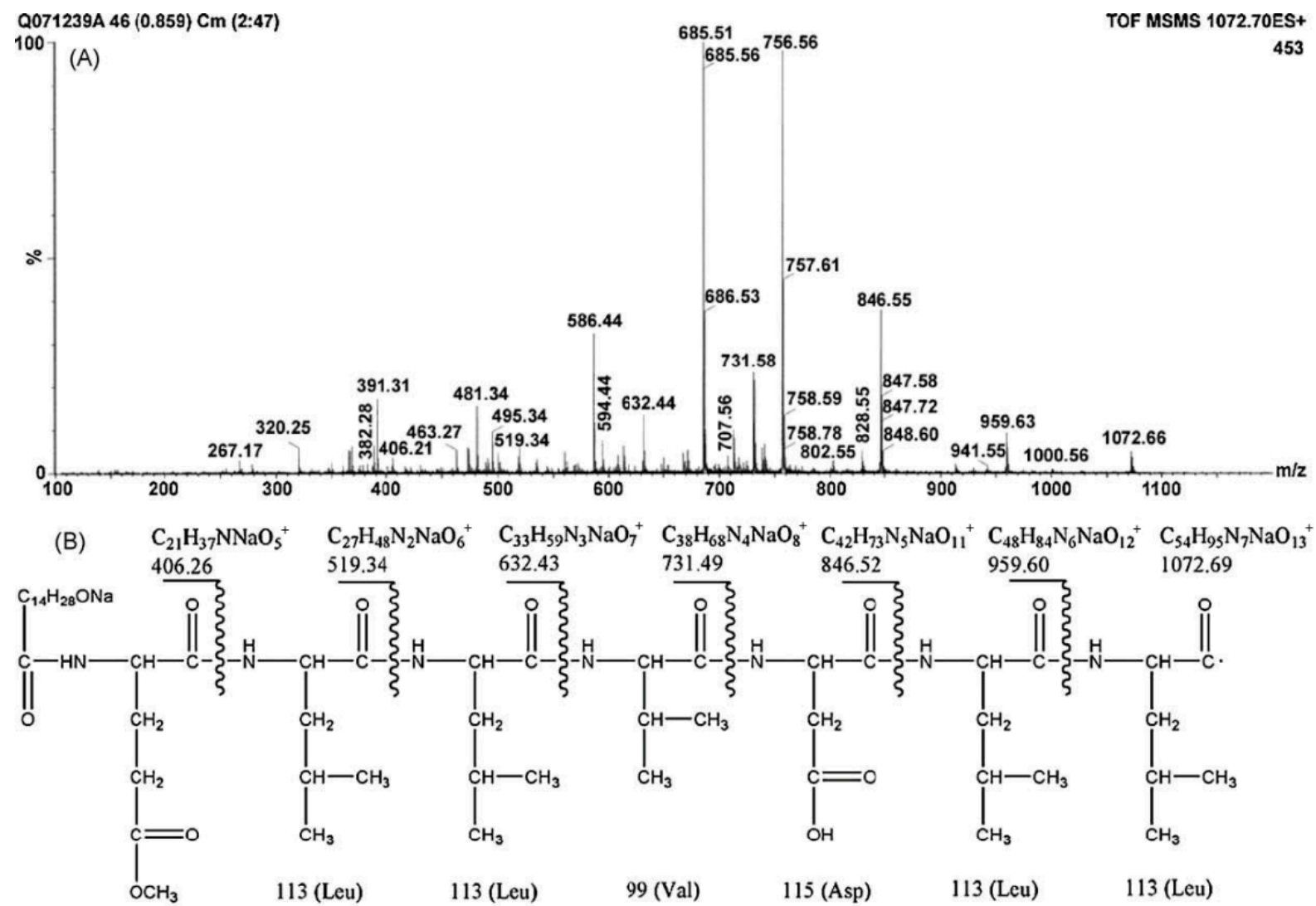

(C)

$\mathrm{C}_{33} \mathrm{H}_{60} \mathrm{~N}_{6} \mathrm{NaO}_{9}^{+} \quad \mathrm{C}_{27} \mathrm{H}_{49} \mathrm{~N}_{5} \mathrm{NaO}_{8}^{+} \quad \mathrm{C}_{21} \mathrm{H}_{38} \mathrm{~N}_{4} \mathrm{NaO}_{7}^{+} \quad \mathrm{C}_{16} \mathrm{H}_{29} \mathrm{~N}_{3} \mathrm{NaO}_{6}^{+} \quad \mathrm{C}_{12} \mathrm{H}_{24} \mathrm{~N}_{2} \mathrm{NaO}_{3}^{+}$
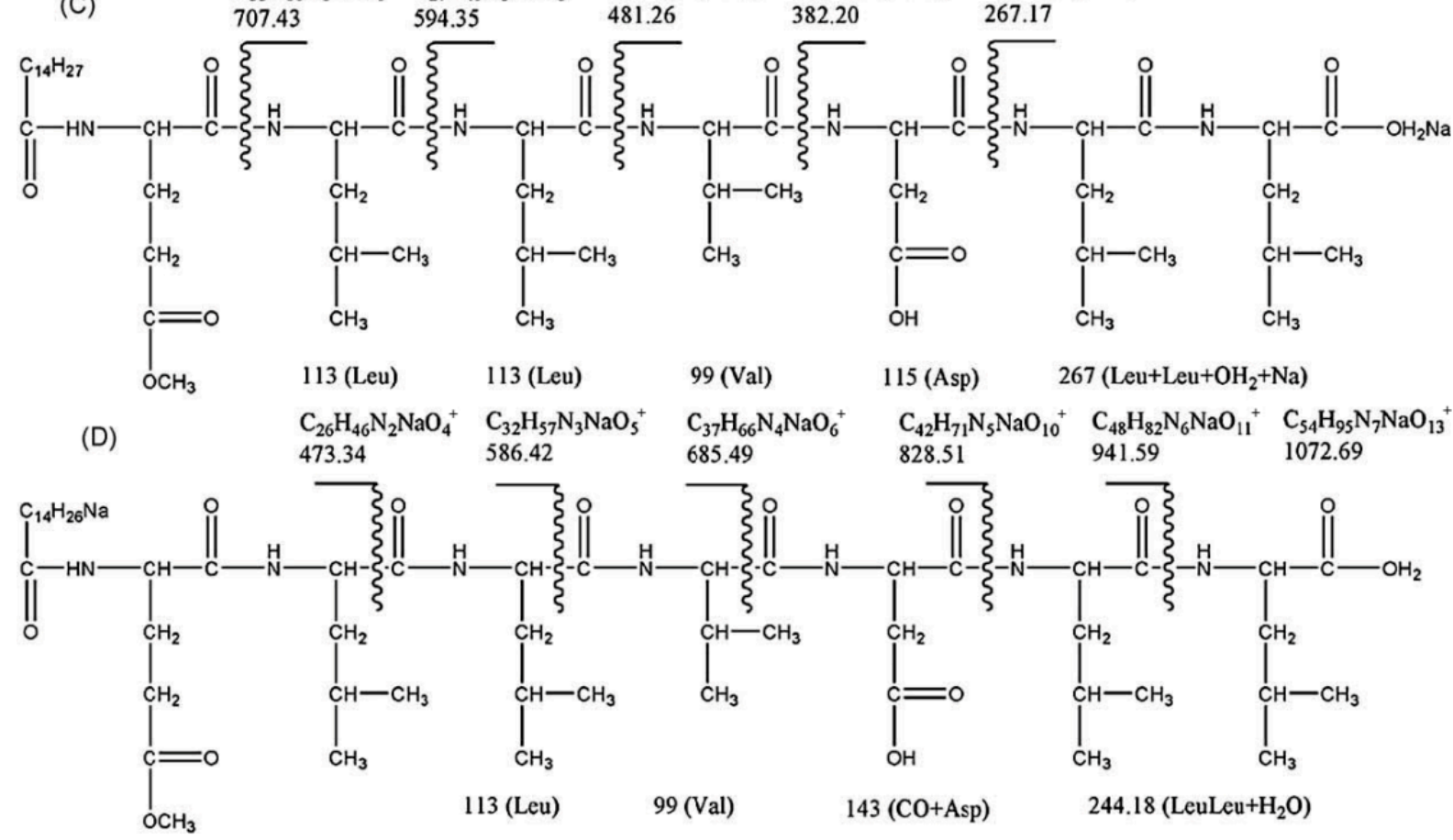

Figure 1. Tandem MS of C15-surfactin-O-methyl ester (A) TOF MS/MS; (B) Fragment ions after simple cleavage; (C,D) fragment ions produced after the double hydrogen transfer of lipopeptides in TOF MS/MS. Reprinted from Process Biochem 44: 1144 [23]. Copyright (2009), with permission from Elsevier. 


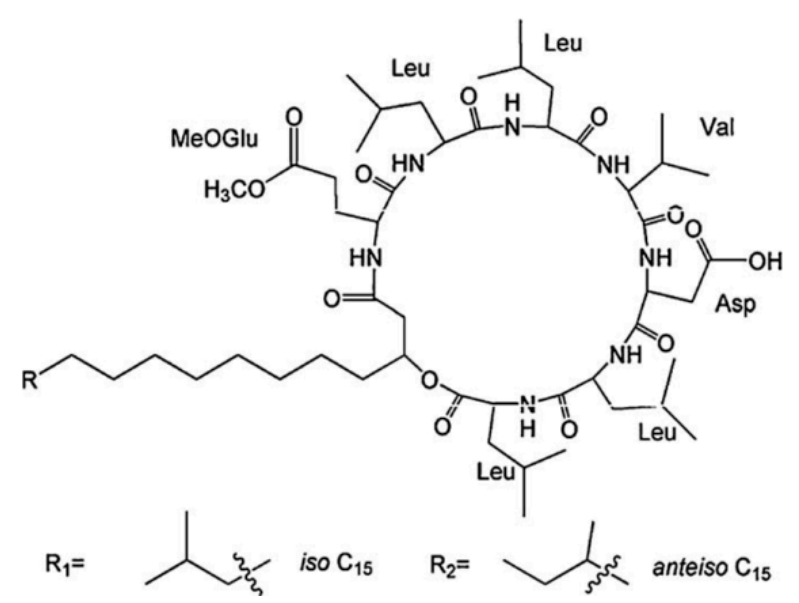

Figure 2. Basic chemical structure of $\mathrm{C} 15$-surfactin- $O$-methyl ester. Reprinted from Process Biochem 44:1144 [23]. Copyright (2009), with permission from Elsevier.

Kowall et al. [24] also reported that B. subtilis produced a total of 44 compounds of surfactins and their monomethyl and dimethyl esters, including the known surfactin variants with L-Leu, L-Val, or L-Ile in position 7 of the peptide ring and unknown variants with leucine residues in position 2 and/or 7 replaced by L-Val and L-Ile.

Different bacterial strains may produce the same surfactin compounds [4], and the same bacterial strains are found to produce lipopeptides belonging to different families as is the case of $B$. subtilis which can produce surfactin, iturin and fenyins simultaneously [25-27].

\subsection{Molecular Behavior at Interface and in Solution}

Much attention has been paid to the study of molecular behavior of surfactin at surface/interface because the biological activity mostly occurs at the interface and is governed by the conformational state of molecules at interfaces [28,29]. The processes involved include adsorption, uptake and transport through biomembrane for assimilation and metabolism of nutrients and pollutants. The molecular organization of surfactin at the interface or surfactin conformation at interface have been experimentally investigated or computationally simulated [30].

\subsubsection{Interfacial Adsorption}

The characteristic of biosurfactant adsorption on the surface and/or interface has attracted more and more attention. The maximum adsorption capacity of $3 \times 10^{18}$ molecule $\cdot \mathrm{m}^{-2}$ (as small as $30 \AA^{2} /$ each molecule) with surfactin concentration of $3 \times 10^{-7} \mathrm{M}$ was detected by Maget-Dana and Ptak [31] which indicate that surfactin molecules at the interface are very closely aligned. Razafindralambo et al. [32] studied the adsorption behavior of surfactin homologues by measuring the dynamic surface tension in the surfactin solution phase and found that the adsorption behavior of surfactin from the bulk water phase was not only concentration-dependent, but also influenced by the length of its fatty acid chain. Ishigami et al. [15] proposed that surfactin molecules could display dimer formation between two surfactin molecules at the air/water interface. Eeman et al. [33] examined the interfacial behavior of cyclic surfactin analogues and concluded that surfactin molecules could rapidly adsorb and organize at 
the interface after a delay time, which were supposed to be caused by the very low concentration in bulk solution and the large interfacial area in this experiment.

These results show that surfactin is an efficient biosurfactant. The rapid adsorption and the close alignment of surfactin on the surface or interface may be contributed to its specific amphiphilic structure with a hydrophobic moiety consisting of a long fatty acid chain and some lipophilic amino acids $\left(\mathrm{Leu}^{2}, \mathrm{Leu}^{3}, \mathrm{Val}^{4}, \mathrm{Leu}^{6}, \mathrm{Leu}^{7}\right)$ and a hydrophilic moiety with the backbone of the cyclic peptide and two anionic residues $\left(\mathrm{Glu}^{1}\right.$ and $\left.\mathrm{Asp}^{5}\right)$. This characteristic enables surfactin to tend to stay at hydrophilic/hydrophobic interfaces and consequently reduce the surface tension of aqueous solutions, which has great implications for adsorption of hydrophobic molecules, and biological assimilation and transport. From this viewpoint, the longer the fatty acid chain is in the hydrophobic moiety of surfactin, the more intensity there is in the repulsive force between water and this fatty acid chain, and hence the fast adsorption of surfactin to the surface/interface. Gang et al. [34] studied the structural and dynamical properties of protonated surfactin molecules at the decane/water interface with molecular dynamics simulation and demonstrated that the peptide rings slightly tilt at the interface and the aliphatic chains exhibited more extended conformation protruding into decane phase, and thus a surfactin molecule would occupy smaller interfacial area. From this viewpoint, surfactin molecules can be closely aligned on the surface and/or interface under certain conditions.

\subsubsection{Monolayer at Interface}

The amphiphilic property of surfactin leads to the formation of stable insoluble monolayer in the gas-liquid interface. Maget-Dana and Ptak [31] showed that, in the acidic subphase, surfactin monolayer existed in three different physical states classified as: liquid expanded (Le) film, plateau region, and solid film. The appearance of peptide ring and fatty acid chain of surfactin molecules changed with the increment of transition pressure from lying on the gas-liquid interface (in the Le film) to gradually erecting (in the plateau region) and completely perpendicular to the interface (in the solid film), respectively. The same result was also obtained by Ishigami et al. [15] except for that the surfactin dimers which were formed due to the hydrophobic interactions between fatty acid chains of surfactin rather than single surfactin molecules behaved at the interface. The subphase temperature and $\mathrm{pH}$ may exert influence on the physical states of monolayer in different ways as the subphase temperature alters the mobility of fatty acid chains and $\mathrm{pH}$ impacts the ionization of peptide loop in surfactins [35-37].

Gallet et al. [30] studied the different conformations of surfactin at a hydrophobic/hydrophilic interface and concluded that the peptide ring was positioned in the plane of the interface with the two acidic chains protruding in the aqueous phase, and the $\beta$-hydroxy fatty acid chain folded to interact mainly with the side chain of $\mathrm{Leu}^{2}$ and also with that of the $\mathrm{Val}^{4}$. This display corresponded to the most stable amphipathic structure representing the surfactin experimental behavior under a condition of weak compression. Similar conclusions were obtained by Gang et al. [38] who studied the properties of protonated surfactin monolayer adsorbed at the air-water interface with molecular dynamics simulation. Whereas, Gang suggested that the hydrophobic tail was favorable to folding back to interact with the $\mathrm{Leu}^{3}$ (not $\mathrm{Leu}^{2}$ ) and $\mathrm{Val}^{4}$ residues. Further, she found that the occurrence of hydrophobic contact between surfactin molecules increased with the interfacial concentration, 
especially the interactions between the hydrophobic tails. The peptide ring backbones exhibited a structural flexibility in that a more packed structure was adopted at a higher interfacial concentration (Figures 3 and 4).

(a)

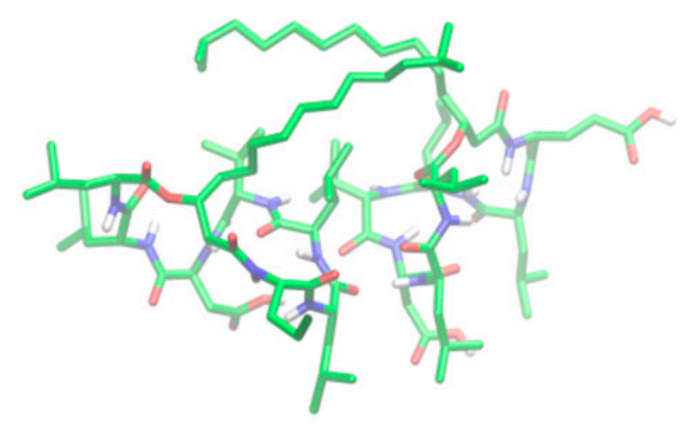

(b)

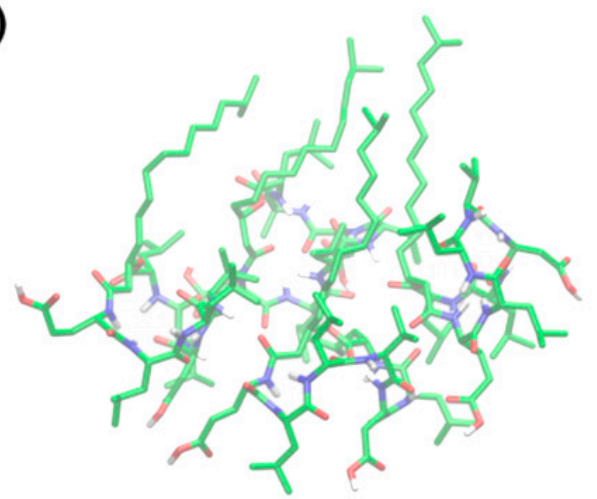

Figure 3. Snapshots of the representative arrangement of surfactin molecules at (a) 2.20 and (b) $1.20 \mathrm{~nm}^{2} \cdot$ molecule $^{-1}$ (The atom coloring scheme is $\mathrm{C}$, green; N, blue; O, red; and H, white). Reprinted with permission from Gang et al. [38]. Copyright (2011) American Chemical Society.

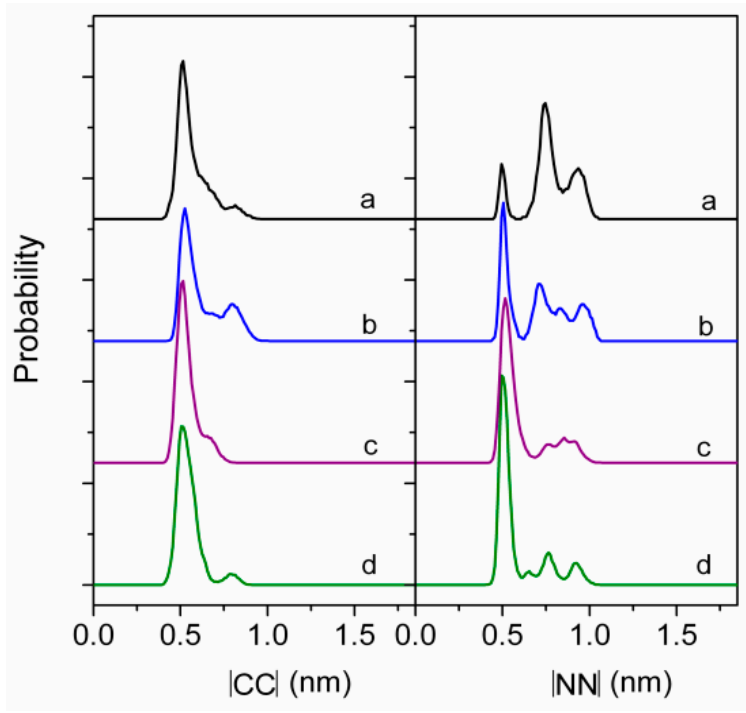

Figure 4. Normalized probability distribution of $\mathrm{CC}$ and $\mathrm{NN}$ magnitudes ( $\mathrm{a}-\mathrm{d}$ corresponds to the interfacial concentration of $2.20,1.50,1.20$, and $0.95 \mathrm{~nm}^{2} \cdot$ molecule ${ }^{-1}$, respectively; $\mathrm{CC}$, the vector connecting the $\beta$ carbon atom of the fatty acid residue and the $\alpha$ carbon atom in $\mathrm{Val}^{4}$; $\mathrm{NN}$, the vector connects the nitrogen atom of $\mathrm{Leu}^{2}$ and the nitrogen atom of $\mathrm{Leu}^{6}$ ). Reprinted with permission from Gang et al. [38]. Copyright (2011) American Chemical Society.

As can be seen from above results, the monolayer of surfactin at interface would be in different physical states at different transition pressures and is mainly influenced by $\mathrm{pH}$ and temperature of the subphase. This characteristic presumably benefits the structural distinction of surfactin. The structural flexibility of the peptide ring backbones (as shown in Figure 4), the interactions of hydrophobic fatty 
acid chain between surfactin molecules as well as the $\beta$-folded structure in the surfactin molecule, are all responsible for the transition of monolayer from one physical state to another. The temperature and $\mathrm{pH}$ of subphase also influence, to less extent, the characteristics of the surfactin monolayer by enhancing of the activity hydrophobic chain (with increase in temperature) and facilitating the ionization of the carboxylic groups of Glu and Asp (with increase in $\mathrm{pH}$ ), respectively.

\subsubsection{Molecular Behavior in Solution}

The molecular behavior of surfactin in solution has been widely studied. Ishigami et al. [15] found that surfactin formed large rod-shaped micelles (micelle weight 179,000, aggregation number $n=173$ ) having a CMC of $9.4 \times 10^{-6} \mathrm{M}$ and $\gamma_{\mathrm{CMC}}$ (surface tension at the $\mathrm{CMC}$ ) of $30 \mathrm{mN} \cdot \mathrm{m}^{-1}$ in $0.1 \mathrm{M}$ $\mathrm{NaHCO}_{3}$ solution. Liu et al. [39] studied the self-aggregation properties of lipopeptide and found that natural surfactin could form sphere-like micelles and some larger aggregates even at extremely low concentrations. Aggregates in surfactin solution prepared in $\mathrm{pH} 7.4$ phosphate buffer were observed to be of two maximum values in hydrodynamic radius one appeared at 4-6 $\mathrm{nm}$ and the other changed with its concentrations as $\sim 85 \mathrm{~nm}$ (at $1.0 \times 10^{-4} \mathrm{M}$ ) and $\sim 108 \mathrm{~nm}$ (at $3.0 \times 10^{-4} \mathrm{M}$ ) [40].

The morphology of surfactin micelle is also affected by $\mathrm{pH}$, metal ions and temperature. Knoblich et al. [41] found that surfactin micelle appeared to be spherical, ellipsoidal and/or cylindrical micelles with a non-homogeneous size distribution at $\mathrm{pH} 7,9.5$, and 12. Furthermore, the cylindrical micelles were transformed into spherical and/or ellipsoidal micelles of smaller sizes by addition of $100 \mathrm{mM} \mathrm{NaCl}$ and $20 \mathrm{mM} \mathrm{CaCl}_{2}$ to a surfactin solution. The effect of counter-ions $\left(\mathrm{Li}^{+}, \mathrm{K}^{+}, \mathrm{Ca}^{2+}\right.$ and $\mathrm{Mg}^{2+}$ ) on micellization behavior was also studied by Li et al. [42] and her results showed that the addition of univalent counter-ions tended to form small and spherical micelle particles, whereas, a small amount of divalent cations encouraged the formation of larger micelle aggregates. She et al. [43] investigated the influence of ambient temperature on the micelle structure and interfacial properties with Molecular Dynamics (MD) simulations and showed that the surface of micelle with sphere structure shrank and the exposure of the hydrocarbon chains increased with the increasing temperature.

Not only the morphology but also the micropolarity and microviscosity of surfactin micelles are found to be affected by extrinsic factors such as $\mathrm{pH}$, temperature and $\mathrm{Ca}^{2+}$. The micropolarity was higher at lower $\mathrm{pH}$ and increased in the presence of $\mathrm{Ca}^{2+}$ while the microviscosity increased with temperature, especially in the presence of $\mathrm{Ca}^{2+}[42,44]$.

The molecular behavior of surfactin in solution is closely relevant to its spatial structure. Three representative 3-D structures had been developed, among which, the S1 (with a single intra-molecular hydrogen bond, $\mathrm{NH}(5)-\mathrm{CO}(2)$, fixing a $\beta$-turn) and $\mathrm{S} 2$ (with three hydrogen bonds, $\mathrm{NH}(7)-\mathrm{CO}(5)$, $\mathrm{NH}(4)-\mathrm{CO}(2)$ and $\mathrm{NH}(6)-\mathrm{CO}$ (carboxyl group), two of them corresponding to $\gamma$-turns) were proposed by Bonmatin et al. [17,45] with surfactin in DMSO solution on the basis of two-dimensional NMR studies combined with molecular modeling and the other one (with three hydrogen bond, $\mathrm{NH}(1)-\mathrm{CO}(7), \mathrm{NH}(4)-\mathrm{CO}(1)$ and $\mathrm{NH}(5)-\mathrm{CO}(1)$ ) was supposed by Tsan et al. [46] with surfactin in sodium dodecyl sulfate (SDS) solution. In both S1 and S2 structures, the backbone ring is characterized by a "horse saddle" topology (Figure 5). Residues 2 and 6, which face each other in the vicinity of the acidic Glu ${ }^{1}$ and $\mathrm{Asp}^{5}$ side-chains, formed a minor polar domain on one side of the ring and residue 4, lipidic chain, as well as side-chains of residues 3 and 7 constructed a major hydrophobic 
domain on the opposite side. In the Tsan's structure (Figure 6), the backbone still adopts a saddle-shaped conformation, with the two acidic residues lying on the same side of the molecule and the hydrophobic residues, except for $\mathrm{Val}^{4}$, are all exposed toward the opposite side which formed a negatively charged area surrounded by a large neutral hydrophobic domain (Figure 6). All these three spatial structures, characterized by both hydrophobic and hydrophilic domains in surfactin molecules, are favorable for auto-association and play a fundamental role for the excellent interfacial activity and physicochemical properties of surfactins.
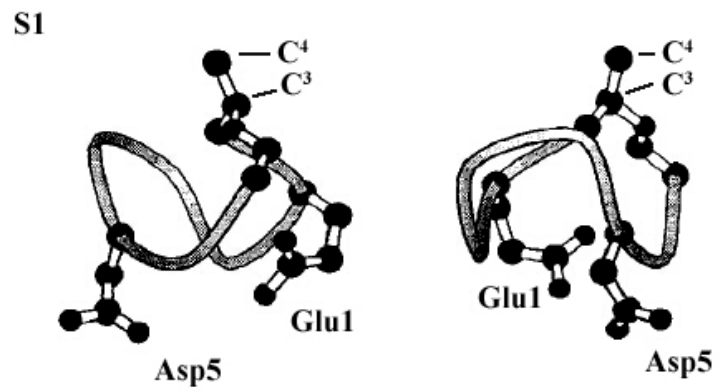

S2

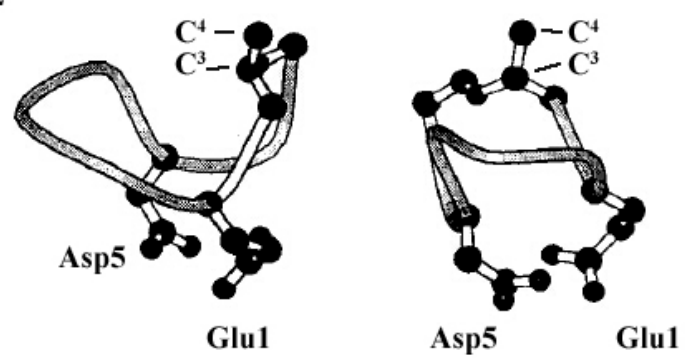

Figure 5. The $\mathrm{S} 1$ (top) and $\mathrm{S} 2$ (bottom) structure (only $\mathrm{Glu}^{1}$ and $\mathrm{Asp}^{5}$ residues have been represented, S1 and S2 exhibit a particular horse saddle folding mode (left) and acidic residues show a claw topology). Reprinted with permission from Bonmatin et al. [45]. Copyright (2004) John Wiley \& Sons, Inc.
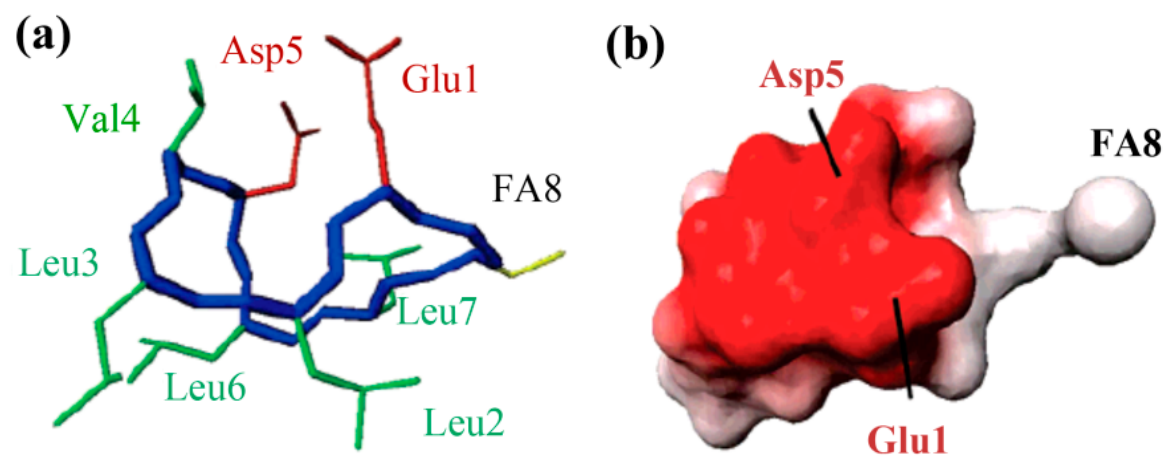

Figure 6. The 3-D structure (a) and Electrostatic potentials associated to solvent-accessible surfaces (b) of surfactin (The backbone is in blue, the two negatively charged side chains are in red, the FA8 fatty acid in yellow, and the other hydrophobic residues in green). Reprinted with permission from Tsan et al. [46]. Copyright (2007) American Chemical Society. 
However, based on the comparative Circular Dichroism Spectroscopy (CD) and Fourier Transform Infrared Spectroscopy (FTIR) spectroscopic studies in different solvents with or without $\mathrm{Ca}^{2+}$ ions, Vass et al. [47] concluded that surfactin had the unique ability of adopting strongly different conformations depending on the ambient conditions.

These results demonstrate that surfactin in solution possess strong self-assembly ability to form micelles and further larger aggregates and the morphology of surfactin micelles formed is notably affected by ambient conditions such as $\mathrm{pH}$, metal ions and temperature.

It is believed that the assembling ability is attributed to the spatial structure with both polar and apolar domains and the $\beta$-sheet formation of surfactin molecules [47,48]. The $\beta$-sheet conformation, occurring through a hydrogen bond between the carbonyl oxygen from a peptide bond and the other amide hydrogen from the same or an adjacent peptide chain, facilitates the formation of micelles and large aggregates. The formation of micelle and aggregates is further enhanced by the hydrophobic interactions between surfactin molecules with a hydrophobic domain comprising of long chain fatty acids as well as some side-chains of amino residues. The influence of $\mathrm{pH}$ on micellization behavior is not fully recognized and the micelle/aggregate morphology is likely not $\mathrm{pH}$-specific [41]. Generally, the breaking of lactone bond and ionization of the two carboxylic groups of Glu and Asp residues in surfactin molecule occurring at high $\mathrm{pH}$ are assumed to be important factors affecting the micellization behavior. The addition of counter-ions would impact the appearance of micelles and aggregates, as supposed, in two ways: (1) Shielding the charge of anions of carboxylic groups which may reduce the substantial surface area of head groups in micelles [41]; (2) Constructing a intermolecular salt-bridge as suggested by the formation of a lichensyin- $\mathrm{Ca}^{2+}$ complex in a molar ratio of $2: 1$, thus facilitating micellization via a dimer assembly, with a possible long-range effect on the spatial structure and morphology of the micelles [49]. Temperature also influences the morphology of surfactin micelles and aggregates, as temperature increases, the stability of the hydrogen bond in the micelles decreases and the dehydration occurs and thus the shape of the peptide rings becomes planar, the solvent accessible surface area decreases and, under high temperature, some hydrocarbon chains reversed their orientation. All these factors consequently induced the changes in the morphology of surfactin micelles and aggregates [43].

\subsection{The Structure-Property Relationship}

Surfactin exhibits a strong surface activity by reducing the surface tension of water to $27 \mathrm{mN} \cdot \mathrm{m}^{-1}$ with a CMC of $10^{-5} \mathrm{M}$ and is the most effective biosurfactant in terms of fundamental dynamic and equilibrium interfacial properties [3]. In addition, surfactin possesses excellent foaming properties to produce and stabilize foam with higher maximum density and stability at a concentration as low as $0.05 \mathrm{mg} / \mathrm{mL}[50]$.

The differences in structure, the carbon length and structure of fatty acid, amino acid composition as well as their sequence in the peptide chain, have some specific impact on the property of surfactins. Generally, surfactins showed a stronger ability in reducing both the dynamic and equilibrium surface tensions with more hydrophobic alkyl chains $[32,33,51]$ and this was typically shown in Figure 7. Also, this phenomenon was found with lichenysin A, another efficient biosurfactant belonging to lipopeptide with a similar primary structure to surfactin of cyclo-(L-Gln ${ }^{1}-\mathrm{D}-\mathrm{Leu}^{2}-\mathrm{L}-\mathrm{Leu}^{3}-\mathrm{L}-\mathrm{V} \mathrm{l}^{4}$-L- 
$\mathrm{Asp}^{5}$-D-Leu ${ }^{6}-\mathrm{L}-\mathrm{Ile} \mathrm{e}^{7}-\beta-\mathrm{OH}$ fatty acid). Surface tension of lichenysin A solution were found to decrease with the increase in the percentage of branched chain fatty acids and increase when the percentage of straight chain 3-hydroxy tetradecanoate increased [52]. With regards to the molecular behavior of surfactin in solution, the micellization and aggregation of a group of surfactin isoforms with different fatty acid chains in water solution were studied by Li et al. [51] and the results indicated that surfactin with short chain of fatty acids tended to form small micelles, and that with chain of long fatty acids tended to form larger micelle aggregates (Figure 8).

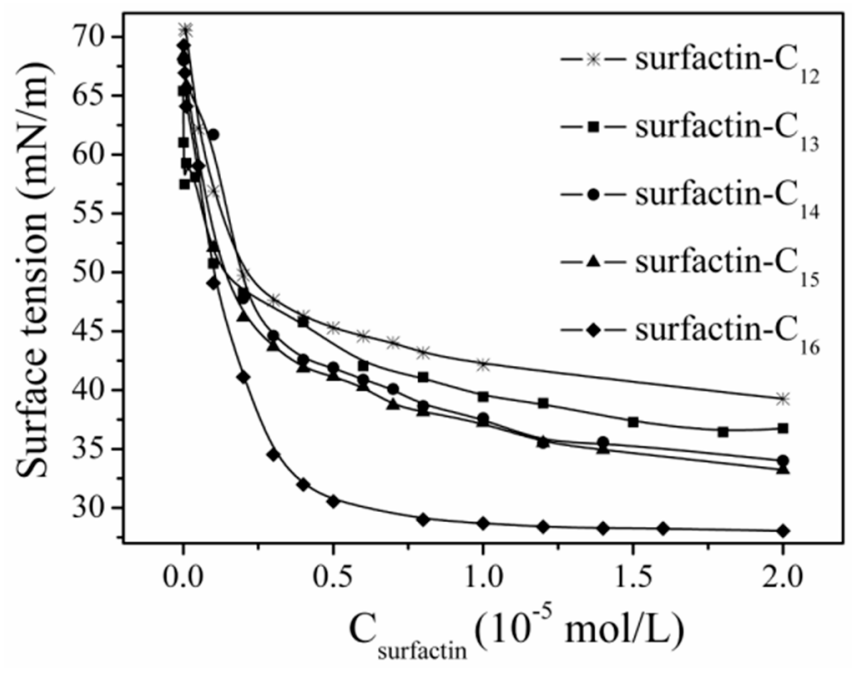

Figure 7. Surface tension of surfactins with different fatty acid chain length [51].
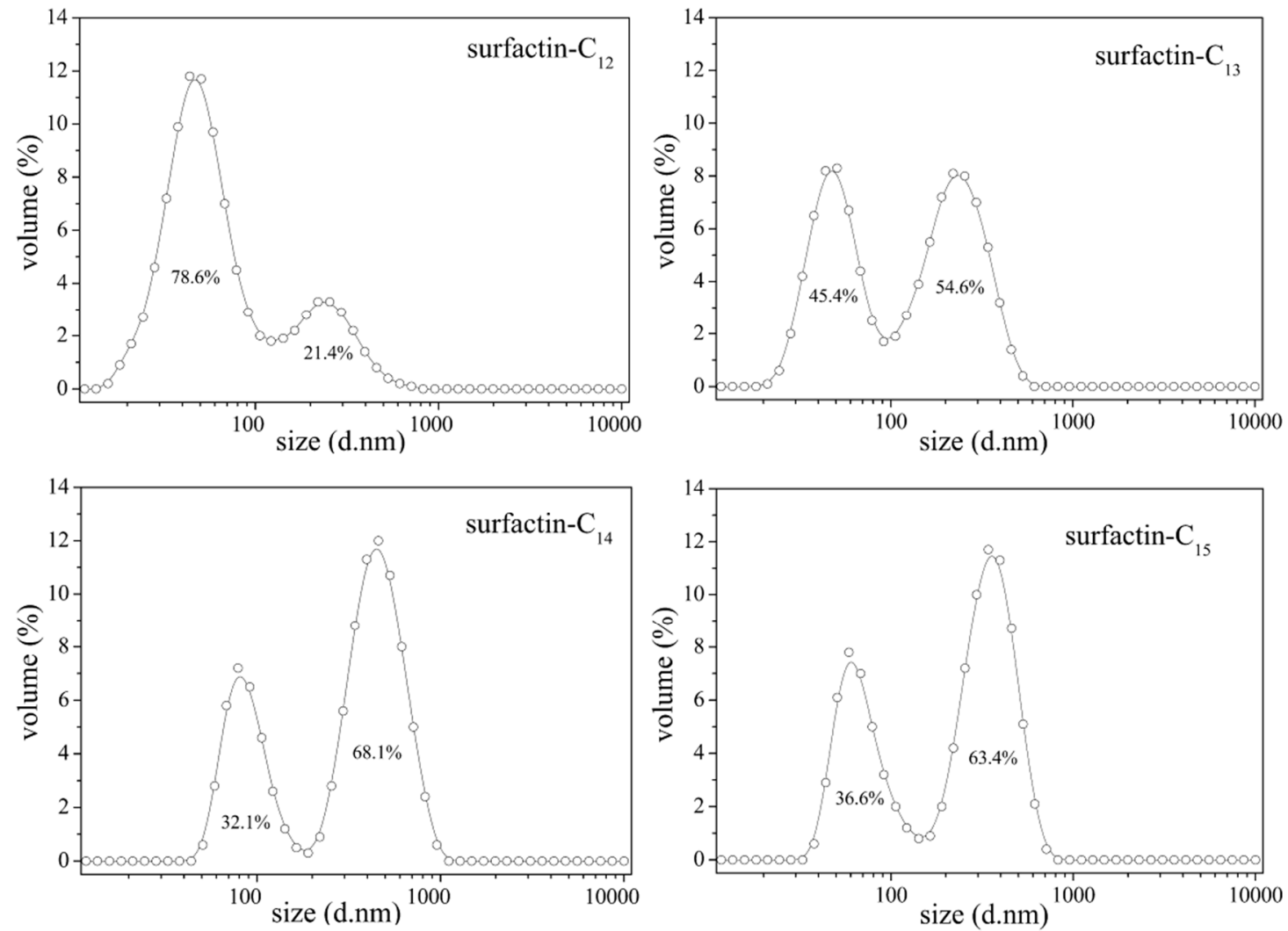

Figure 8. Micelle size distribution of surfactin-C13, -C14 and -C15 [51]. 
Linear surfactin shows lower surface activities and poor hemolytic activities compared to those of cyclic structures [53]. Eeman et al. [33] found that the opening of the peptide ring reduced the surface activity. Morikawa et al. [54] demonstrated that the oil displacement activities of linear surfactin, prepared by saponification of the lactone ring, decreased to one third of its parent cyclic surfactin. This difference confirmed the hypothesis that the "horse saddle" structure of surfactin with distinct polar and apolar domains played an important role in surfactin properties. Interestingly, surfactin-C15 conformers were found to possess the same oil displacement activities even though they showed different minimum surface tensions [54]. These results implied that surfactin conformers would have different structures in water, but the same structure at the water-oil interface.

The two Glu and Asp residues present in the cycle of surfactins play a critical role in their amphiphilic properties. Liu et al. [23] studied the surface activity of C15-surfactin- $O$-methyl ester (Figure 2) with comparison of $\mathrm{C} 15$-surfactin and found that $\mathrm{C} 15$-surfactin- $O$-methyl ester had a stronger surface activity than $\mathrm{C} 15$-surfactin. C15-surfactin- $O$-methyl ester showed $\mathrm{CMC}$ of $9.78 \times 10^{-6} \mathrm{M}$ and surface tension at $\mathrm{CMC}\left(\gamma_{\mathrm{CMC}}\right)$ of $28.71 \mathrm{mN} / \mathrm{m}$ in $10 \mathrm{mM}$ phosphate buffered saline $\left(\mathrm{pH} 8.0,25.0^{\circ} \mathrm{C}\right)$, whereas, C15-surfactin was characterized with CMC of $1.74 \times 10^{-5} \mathrm{M}$ and $\gamma_{\mathrm{CMC}}$ of $30.03 \mathrm{mN} / \mathrm{m}$ under the same conditions. Morikawa et al. [54] found that the activity increased by $20 \%$ when the Glu and Asp residues were both methylated or amidated, and decreased drastically when these two residues were modified by aminomethane sulfonic acid. Thimon et al. [55] studied the surface properties of the chemically modified (Glu $\gamma$-methyl ester) surfactin and found this variant showed a lower CMC than the mother surfactin. It was also confirmed that the surface activity of monoanionic biosurfactants (e.g., lichenysin A with asparagine in position 5) was higher than that of dianionic biosurfactants (e.g., surfactin with aspartate in position 5) [56,57]. Grangemard et al. [49] conducted a comparative study on the properties of lichenysin produced by $B$. licheniformis with the surfactin produced by $B$. subtilis (with similar primary structure but different in $\mathrm{Glu}^{1}$ and $\mathrm{Leu}^{7}$ in surfactin, Gln ${ }^{1}$ and Ile $^{7}$ in lichenysin) and found that lichenysin was with a higher surfactant power (CMC, $22 \mu \mathrm{M})$ than surfactin (CMC, $220 \mu \mathrm{M})$.

In terms of the role of amino acids in the modulations of activities, Bonmatin studied the properties of surfactin modifiers with the substitution of the L-valine ${ }^{4}$ by a more hydrophobic residue, i.e., leucine or isoleucine and found that these $\mathrm{Leu}^{4}$ - and $\mathrm{Ile}^{4}$-surfactins had a higher affinity for hydrophobic solvents and a twofold decrease of CMC [58]. In light of the three-dimensional structure, the residue 4 side-chain was proposed to be aligned along the direction of the lipid tail, so it reinforces the hydrophobic side and, hence, plays a critical role in surfactant activity. Also, experiment results showed that the surface activity was increased and CMC decreased when the amino acids of surfactin were changed to more hydrophobic ones $[4,58,59]$.

The ambient $\mathrm{pH}$ also affects the surface/interface property of surfactin markedly. Surfactins show higher activity under alkaline conditions than under acidic conditions. When aspartic acid residues and glutamic acid of surfactins were amido-esterified or methyl-esterified, the obtained derivatives retained similar activities irrespective of the $\mathrm{pH}$ changes [54].

Surfactin, with $\beta$-hydroxy fatty acids linked to a heptapeptide (L-Glu ${ }^{1}-\mathrm{L}-\mathrm{Leu}^{2}$-D-Leu ${ }^{3}$-L-Val ${ }^{4}$-L$\mathrm{Asp}^{5}$-D-Leu ${ }^{6}-\mathrm{L}-\mathrm{Leu}^{7}$ ), obviously presents the amphiphilic character. Based on all experimental data mentioned above, the three-dimensional structures proposed by Bonmatin et al. [45] and Tsan et al. [46], characterized by the formation of both the hydrophilic domain and hydrophobic domain, substantially 
account for the activities of surfactin. This was confirmed by two facts: (1) the fatty acid chain plays a fundamental role in formation of supramolecular structures such as micelles or "oligomers" through intermolecular hydrophobic interactions; (2) the carboxylic groups of both glutamate and aspartate, the polar domain, in surfactin molecules in the aggregation process, plays the predominant role in the properties of surfactin. It would be more reasonable to conclude that the solubility and surfactant activities of surfactin depend on the precise distribution of the residues forming the two respective domains.

\section{Potential Applications}

During the last few years, there has been an increasing demand for biosurfactants used as emulsifiers, de-emulsifiers, wetting agents, spreading agents, foaming agents, functional food ingredients and detergents. Recently, due to several major advantages over chemical surfactants-lower toxicity, high environmental compatibility, biodegradability, and synthesis from renewable raw materials — biosurfactants have been becoming the focus of extensive research and applications from food industries to oil industries.

\subsection{Microbial Enhanced Oil Recovery (MEOR)}

MEOR is considered as a tertiary oil recovery technology that uses microorganisms and their metabolites to mobilize residual oil in oil reservoirs which is trapped in porous rocks by capillary force [60]. Due to the fact that capillary force is believed to be proportional to the interfacial tension (IFT) between oil and water and that biosurfactants are effective in reducing capillary forces by the reduction of oil-water interfacial tension and wettability alteration [61,62] and in forming micelles, biosurfactants, thus, possess the capability to facilitate mobilization of the entrapped oil in reservoirs $[1,63]$.

Recent studies have shown that IFT reduction and wettability alteration are important mechanisms for MEOR [64,65]. Further, Sarafzadeh et al. [61] conducted several different tests to quantify the individual effects of the IFT reduction and wettability alteration on the efficiency of MEOR using E. cloacae and concluded that wettability alteration played a more significant role in improving oil recovery for both ex situ and in situ scenarios than IFT reduction. In addition, Sarafzadeh's results showed that wettability alteration was changed mainly by biosurfactant adsorption on the concerning rock.

Various experiments with laboratory-scale of sand-packed columns and field trials have successfully demonstrated the effectiveness of biosurfactants in MEOR. Use of biosurfactants in MEOR can be implemented in two different ways as either an ex situ biosurfactant injection or in situ biosurfactant production to achieve increase in oil recovery from subsurface reservoirs [66]. Both of them require that biosurfactants and their producing microorganisms are able to tolerate the harsh environmental conditions, such as high salinities, temperatures, and pressures. Possessing extremely advantageous features, including lower toxicity, higher biodegradability and effectiveness at extreme temperature, salinity and $\mathrm{pH}$ conditions as well as high interfacial activities together with low CMCs, surfactin is the most promising candidate in MEOR [66].

Surfactins can maintain activities under harsh conditions and recover sand trapped oil. Al-Wahaibi et al. [67] reported that surfactin from isolate B30 could form stable emulsions with light and heavy crude oil, and enhance oil recovery by $17 \%-31 \%$. Meanwhile, this surfactin was proved to 
be stable over a wide range of $\mathrm{pH}$, salinity and temperatures [67]. Schaller et al. [68] concluded that surfactin was active under harsh conditions with $\mathrm{NaCl}$ concentration of $0 \%-10 \%, \mathrm{pH} 3-10$ and temperature of $21-70{ }^{\circ} \mathrm{C}$. Makkar and Cameotra [69] found that B. subtilis produced surfactin at high temperatures which could emulsify diesel with $90 \% \mathrm{E}_{24}$ and recover $62 \%$ of oil entrapped in sand core. All of the above results show the potential of surfactins for MEOR.

Biosurfactant-producing microorganisms can survive and produce biosurfactant in in situ conditions of oil reservoirs. By inoculation to oil reservoirs with Bacillus strains and/or nutrients, Youssef et al. [70] confirmed that the Bacillus strains tested could produce lipopeptides with an average concentration of $90 \mathrm{mg} / \mathrm{L}$ in the oil reservoir, which was approximately nine times the minimum concentration required to mobilize the entrapped oil from sandstone cores. Besides, the microbial metabolism and in-situ biosurfactant production as well as concomitant increase in oil production were observed and, thus, the metabolic activity of injected biosurfactant-producing microorganisms was confirmed [71].

In the past decades, about 10 MEOR applications have been implemented in Malaysia, USA, Argentina, and China and a successful MEOR field test was observed with oil reservoir temperatures below $55{ }^{\circ} \mathrm{C}$, salinity less than $100,000 \mathrm{ppm}$, water cut above $75 \%$, and a low production rate [72]. Maudgalya et al. reviewed 26 biosurfactant-related field trials of MEOR and found that 20 of them (77\%) were positive in oil production [73]. Till now, one of the most encouraging results of MEOR was found in Shengli oil field, China, with production of $9.75 \times 10^{4} \mathrm{t}$ additional crude oil over 10 years [74]. With almost a century of research and field trials, MEOR has shown great potential in enhancing oil production and extending the economic life of an oilfield.

\subsection{Oil Spill Contamination and Remediation}

Oil spills are one of the major causes of oil pollution in marine environments. Due to the toxic and persistent characteristics, chemically synthesized surfactants are not favored as remediating agents.

Biosurfactant is a potential alternative for bioremediation of crude oil contamination and oil spills in marine environments and other terrestrial ecosystems for its excellent surface activity and emulsifying properties as well as lower CMC characteristics. It has been shown that from the above CMC, stable aggregates are formed (called micelles) which can increase the solubility of hydrophobic organic contaminants, providing opportunities for phyto- or microbial remediation. The ability of biosurfactants in emulsifying hydrocarbons into water to form mixtures has been widely reported [75]. These emulsification properties are believed to facilitate hydrocarbon release, solubilization, assimilation and degradation by flora and fauna in the environment, the very fundamentals for oil spill cleanup [76]. Several biosurfactants have found successful applications in environmental remediation such as rhamnolipids [77], lichenysins [78] and surfactin [14,79]. Kim et al. [80] isolated a new bacterial strain from a crude oil sample collected in an oil spill contaminated area, and found that the biosurfactant produced by this strain showed good emulsification activities on paraffin and crude oil. The addition of biosurfactant-containing remediation agent to seawater stimulated the degradation of crude oil by the indigenous marine bacteria as well as the removal of crude oil from the surface of contaminated sea sand [81]. Meanwhile, biosurfactant is capable of disrupting oil slicks floating on the water surface, promoting oil dispersion, generating stable emulsion and thus greatly enhancing its biodegradation by indigenous marine microorganisms [82] as well as enhancing the attachment of bacteria to oil layers to 
increase the uptake and metabolisms of oil hydrocarbons [83]. These factors indicate that biosurfactants have a strong potential for applications in cleaning up oil spills at sea and on shorelines.

Biosurfactants produced by one consortium of microorganisms may enhance the biodegradation of oil hydrocarbons by other microorganisms. Considering the ubiquitous existence of marine hydrocarbon-degrading bacteria - the obligate hydrocarbonoclastic bacteria (OHCB) which have been recognized and shown to play a significant role in the biological removal of petroleum hydrocarbons from polluted marine waters [84-86] - biosurfactant added to or produced in situ in the contaminated environment will be of great significance in the oil clean up. Laboratory studies have shown that the addition of biosurfactant mixtures alone is useful for stimulating biodegradation of hydrocarbon contaminants in the environment [87]. The wide range of hydrocarbonoclastic capabilities of bacterial consortium leads to the degradation of both aromatic and aliphatic fractions of the crude oil [88]. The effectiveness for in situ bioremediation of oil contaminated soil by biosurfactant-producing B. subtilis was also demonstrated [89].

Generally, oil-degrading microorganisms have the capacity to produce biosurfactants to facilitate their growth by enhancing assimilation of hydrocarbons and nutrients available from the environment. Even in the cold oceanic environment, some oil-degrading strains can thrive and degrade oil normally and the low temperature had no obvious effects on the hydrocarbon degrading bacteria community and the bioremediation process [90]. A number of hydrocarbon-degrading microorganisms are reported to produce emulsifying agents and some of these bioemulsifiers have been considered for use in oil cleaning operations and other applications at low temperature.

Biosurfactants were experimentally investigated for their ability in facilitating the removal of adherent oil from Alaskan beaches and results demonstrate that microbial surfactants released oil to a significantly greater extent (two to three times) than water alone [91]. The ability of dispersing oil slicks into fine droplets, converting mousse oil into oil-in-water emulsion and washing oil away from oil entrapped sand has been shown with convincing results [87]. Due to the lower CMC than their chemical counterparts, biosurfactants are the suitable candidate for use in oil spill treatments and mitigation.

The results of field experiments and trials following actual spill incidents have been reviewed by Swannell et al. [92]. The oil-degrading microorganisms in the marine environment are well established and research has demonstrated the capability of the indigenous microflora to degrade many chemical components of the petroleum shortly after exposure. Application of fertilizers can also effectively stimulate the biodegradation rates of oil. The ratio of oil loading to nitrogen concentration is considered to be the principal controlling factor of this bioremediation strategy in field.

Evaluation methods have been established [93]. Dispersion effectiveness of surfactins was evaluated by measuring the CMC and dispersant-to-oil ratio (DOR). For surfactins, the CMC values in double deionized distilled water were lower than that in the sea salt solution, which has been partly attributed to saline-induced conformational changes in the solvated ionic species of the biosurfactants. The DORs for surfactin were 1:96 in water, much higher than that in 12 ppt sea salt of 1:30, suggesting a reduction in oil dispersing efficiency of surfactant in saline. 


\subsection{Other Applications}

Being amphiphilic membrane active biosurfactants, surfactin, fengycin and iturin compounds are found to be of potent antimicrobial activities. Iturin are potent antifungal agents which can be used as biopesticides for plant protection. Iturin A produced by B. subtilis RB14 was shown to be effective for the control of damping-off caused by $R$. solani in tomato plants [94]. B. subtilis 20B showed antifungal activity against mycelia growth of $C$. indicum, A. burnsii, F. oxysporium, F. udum, T. herzanium and R. bataticola [95]. Surfactin of B. subtilis have the most potent antibiotic activity [4] and that from $B$. licheniformis inhibits germination of $M$. grisea [96]. Bechard et al. [97] demonstrated that lipopeptide from $B$. subtilis possessed a broad spectrum of activity against Gram-negative bacteria, little activity against Gram-positive organisms, as well as one fungi assayed.

Taking into consideration the amphiphilic nature of these lipopeptides, the above-mentioned activities are presumably believed to be a direct consequence of the interaction of lipopeptide with its target membrane and the alteration of the bilayer properties. The interaction of lipopeptides with membrane lipids may form a pore which causes cellular leakage [98,99]. Carrillo et al. [100] observed that the incorporation of surfactin into POPC membranes induced a strong dehydration of the phospholipid $\mathrm{C}=\mathrm{O}$ groups and a strong interaction with the phospholipid acyl chains and all these interactions finally result in loss of vesicular contents, or "pore" formation which consequently induces content leakage. It was believed that cyclic peptides killed Gram-positive and Gram-negative bacteria in this way [101].

Also, biosurfactants have found application or prospect in cosmetics [102], the food industry [103], the environment [104-106], pharmaceuticals [6,7,107], and biological control of harmful microorganisms in agriculture [108,109].

\section{Conclusions}

Biosurfactants are a unique class of microbial metabolites with surface-active properties. The differences in the sequence of amino acids and carbon atoms in the fatty acids provide surfactins with diverse chemical structures and physiochemical properties. The amphiphilic characteristics of surfactin molecules enable them to have a strong tendency to adsorb to hydrophilic/hydrophobic interfaces and, consequently, reduce the surface tension of aqueous solutions, leading to the formation of a stable insoluble monolayer in the gas-liquid interface. The physical states of this monolayer are influenced by subphase temperature and $\mathrm{pH}$. The fact that surfactins exhibit a strong self-assembly ability to form micelles and some larger aggregates, even at rarely low concentrations, can be reasonably explained by these three typical 3-D structures that are developed. The amphiphilic and surface properties of surfactins are certainly related to the existence of the minor hydrophilic and major hydrophobic domains as described in the three 3-D conformations. Recently, due to several advantages over chemical surfactants such as lower toxicity, high environmental compatibility, biodegradability, and synthesis from renewable raw materials, biosurfactants have been the focus of extensive research and applications, especially in microbial enhanced oil recovery as well as remediation of oil spills. 


\section{Acknowledgments}

This work is supported by the National High Technology Research and Development Program of China (863 Program) (Grant No. 2013AA064403) and by the National Natural Science Foundation of China (No. 41273084).

\section{Author Contributions}

Jin-Feng Liu, Ji-Dong Gu and Bo-Zhong Mu prepared the manuscript; Serge Maurice Mbadinga and Shi-Zhong Yang contributed to draft the section describing the application of biosurfactants and the section on the structure and property of biosurfactants, respectively. All authors have read and approved this manuscript submitted.

\section{Conflicts of Interest}

The authors declare no conflict of interest.

\section{References}

1. Desai, J.D.; Banat, I.M. Microbial production of surfactants and their commercial potential. Microbiol. Mol. Biol. Rev. 1997, 61, 47-64.

2. Silva, R.D.C.F.S.; Almeida, D.G.; Rufino, R.D.; Luna, J.M.; Santos, V.A.; Sarubbo, L.A. Applications of biosurfactants in the petroleum industry and the remediation of oil spills. Int. J. Mol. Sci. 2014, 15, 12523-12542.

3. Deleu, M.; Razafindralambo, H.; Popineau, Y.; Jacques, P.; Thonart, P.; Paquot, M. Interfacial and emulsifying properties of lipopeptides from Bacillus subtilis. Colloids Surf. Physicochem. Eng. Asp. 1999, 152, 3-10.

4. Peypoux, F.; Bonmatin, J.M.; Wallach, J. Recent trends in the biochemistry of surfactin. Appl. Microbiol. Biotechnol. 1999, 51, 553-563.

5. Grgurina, I. Lipopeptide secondary metabolites from the phytopathogenic bacterium Pseudomonas syringae. In Advances in Microbial Toxin Research and Its Biotechnological Exploitation; Upadhyay, R., Ed.; Springer US: New York, NY, USA, 2002; pp. 105-140.

6. Baltz, R.H.; Miao, V.; Wrigley, S.K. Natural products to drugs: Daptomycin and related lipopeptide antibiotics. Nat. Prod. Rep. 2005, 22, 717-741.

7. Hino, M.; Fujie, A.; Iwamoto, T.; Hori, Y.; Hashimoto, M.; Tsurumi, Y.; Sakamoto, K.; Takase, S.; Hashimoto, S. Chemical diversity in lipopeptide antifungal antibiotics. J. Ind. Microbiol. Biotechnol. 2001, 27, 157-162.

8. Liu, X.Y.; Yang, S.Z.; Mu, B.Z. Molecular structures of microbial lipopeptides. Biotechnol. Bull. $\mathbf{2 0 0 5}, 4,18-26$.

9. Arima, K.; Kakinuma, A.; Tamura, G. Surfactin, a crystalline peptide-lipid surfactant produced by Bacillus subtilis, isolation, characterization and its inhibition of fibrin clot formation. Biochem. Biophys. Res. Commun. 1968, 31, 488-494. 
10. Yakimov, M.M.; Abraham, W.-R.; Meyer, H.; Laura, G.; Golyshin, P.N. Structural characterization of lichenysin a components by fast atom bombardment tandem mass spectrometry. Biochim. Biophys. Acta 1999, 1438, 273-280.

11. Peypoux, F.; Guinand, M.; Michel, G.; Delcambe, L.; Das, B.C.; Lederer, E. Structure of iturin A, a peptidolipid antibiotic from Bacillus subtilis. Biochemistry 1978, 17, 3992-3996.

12. Vanittanakom, N.; Loeffler, W.; Koch, U.; Jung, G. Fengycin-A novel antifungal lipopeptide antibiotic produced by Bacillus subtilis F-29-3. J. Antibiot. 1986, 39, 888-901.

13. Lang, S. Biological amphiphiles (microbial biosurfactants). Curr. Opin. Colloid Interface Sci. 2002, 7, 12-20.

14. Rosenberg, E.; Ron, E.Z. High- and low-molecular-mass microbial surfactants. Appl. Microbiol. Biotechnol. 1999, 52, 154-162.

15. Ishigami, Y.; Osman, M.; Nakahara, H.; Sano, Y.; Ishiguro, R.; Matsumoto, M. Significace of $\beta$-sheet formation for micellization and surface adsorption of surfactin. Colloids Surf. B 1995, 4, 341-348.

16. Kakinuma, A.; Hori, M.; Isono, M.; Tamura, G. Determination of amino acid sequence in surfaction, a crystalline peptide lipid surfactant produced by Bacillus subtilis. Agric. Biol. Chem. 1969, 33, 971-972.

17. Bonmatin, J.-M.; Laprevote, O.; Peypoux, F. Diversity among microbial cyclic lipopeptides: Iturins and surfactins: Activity-structure relationships to design new bioactive agents. Comb. Chem. High Throughput Screen 2003, 6, 541-556.

18. Baumgart, F.; Kluge, B.; Ullrich, C.; Vater, J.; Ziessow, D. Identification of amino acid substitutions in the lipopeptide surfactin using 2D NMR spectroscopy. Biochem. Biophys. Res. Commun. 1991, 177, 998-1005.

19. Yang, S.Z.; Wei, D.Z.; Mu, B.Z. Determination of the amino acid sequence in a cyclic lipopeptide using MS with DHT mechanism. J. Biochem. Biophys. Methods 2006, 68, 69-74.

20. Yang, S.Z.; Wei, D.Z.; Mu, B.Z. Determination of the structure of the fatty acid chain in a cyclic lipopeptide using GC-MS. J. Biochem. Biophys. Methods 2007, 70, 519-523.

21. Liu, X.Y.; Haddad, N.I.A.; Yang, S.Z.; Mu, B.Z. Structural characterization of eight cyclic lipopeptides produced by Bacillus subtilis HSO121. Protein Pept. Lett. 2007, 14, 766-773.

22. Liu, X.Y.; Yang, S.Z.; Mu, B.Z. Isolation and characterization of a C12-lipopeptide produced by Bacillus subtilis HSO 121. J. Pept. Sci. 2008, 14, 864-875.

23. Liu, X.Y.; Yang, S.Z.; Mu, B.Z. Production and characterization of a C15-surfactin-O-methyl ester by a lipopeptide producing strain Bacillus subtilis HSO121. Process Biochem. 2009, 44, 1144-1151.

24. Kowall, M.; Vater, J.; Kluge, B.; Stein, T.; Franke, P.; Ziessow, D. Separation and characterization of surfactin isoforms produced by Bacillus subtilis okb 105. J. Colloid Interface Sci. 1998, 204, 1-8.

25. Jacques, P.; Hbid, C.; Destain, J.; Razafindralambo, H.; Paquot, M.; de Pauw, E.; Thonart, P. Optimization of biosurfactant lipopeptide production from Bacillus subtilis $\mathrm{S} 499$ by plackett-burman design. Appl. Biochem. Biotechnol. 1999, 77, 223-233.

26. Kim, P.I.; Ryu, J.; Kim, Y.H.; Chl, Y.-T. Production of biosurfactant lipopeptides iturin A, fengycin, and surfactin A from Bacillus subtilis CMB32 for control of colletotrichum gloeosporioides. J. Microbiol. Biotechnol. 2010, 20, 138-145. 
27. Athukorala, S.N.P.; Fernando, W.G.D.; Rashid, K.Y. Identification of antifungal antibiotics of Bacillus species isolated from different microhabitats using polymerase chain reaction and MALDI-TOF mass spectrometry. Can. J. Microbiol. 2009, 55, 1021-1032.

28. Infante, M.R.; Moses, V. Synthesis and surface activity properties of hydrophobic/hydrophilic peptides. Int. J. Pept. Protein Res. 1994, 43, 173-179.

29. Kaiser, E.T.; Kezdy, F.J. Amphiphilic secondary structure: Design of peptide hormones. Science (New York, NY) 1984, 223, 249-255.

30. Gallet, X.; Deleu, M.; Razafindralambo, H.; Jacques, P.; Thonart, P.; Paquot, M.; Brasseur, R. Computer simulation of surfactin conformation at a hydrophobic/hydrophilic interface. Langmuir 1999, 15, 2409-2413.

31. Maget-Dana, R.; Ptak, M. Interfacial properties of surfactin. J. Colloid Interface Sci. 1992, 153, 285-291.

32. Razafindralambo, H.; Thonart, P.; Paquot, M. Dynamic and equilibrium surface tensions of surfactin aqueous solutions. J. Surfactants Deterg. 2004, 7, 41-46.

33. Eeman, M.; Berquand, A.; Dufrene, Y.; Paquot, M.; Dufour, S.; Deleu, M. Penetration of surfactin into phospholipid monolayers: Nanoscale interfacial organization. Langmuir 2006, 22, 11337-11345.

34. Gang, H.Z.; Liu, J.F.; Mu, B.Z. Interfacial behavior of surfactin at the decane/water interface: A molecular dynamics simulation. J. Phys. Chem. B 2010, 114, 14947-14954.

35. Song, C.S.; Ye, R.Q.; Mu, B.Z. Effect of compression speed on aggregation behavior of surfactin in langmuir monolayer. Acta Chim. Sin. 2009, 69, 2038-2042.

36. Song, C.S.; Ye, R.Q.; Mu, B.Z. Aggregation behavior and surface morphology studies of surfactin in langmuir-blodgett films. Colloids Surf. Physicochem. Eng. Asp. 2008, 330, 49-54.

37. Song, C.S.; Ye, R.Q.; Mu, B.Z. Molecular behavior of a microbial lipopeptide monolayer at the air-water interface. Colloids Surf. Physicochem. Eng. Asp. 2007, 302, 82-87.

38. Gang, H.Z.; Liu, J.F.; Mu, B.Z. Molecular dynamics study of surfactin monolayer at the air/water interface. J. Phys. Chem. B 2011, 115, 12770-12777.

39. Liu, J.; Zou, A.H.; Mu, B.Z. Toluidine blue: Aggregation properties and distribution behavior in surfactin micelle solution. Colloids Surf. B. Biointerfaces 2010, 75, 496-500.

40. Han, Y.; Huang, X.; Cao, M.; Wang, Y. Micellization of surfactin and its effect on the aggregate conformation of amyloid $\beta$ (1-40). J. Phys. Chem. B 2008, 112, 15195-15201.

41. Knoblich, A.; Matsumoto, M.; Ishiguro, R.; Murata, K.; Fujiyoshi, Y.; Ishigami, Y.; Osman, M. Electron cryo-microscopic studies on micellar shape and size of surfactin, an anionic lipopeptide. Colloids Surf. B. Biointerfaces 1995, 5, 43-48.

42. Li, Y.; Zou, A.H.; Ye, R.Q.; Mu, B.Z. Counterion-induced changes to the micellization of surfactin- $C-16$ aqueous solution. J. Phys. Chem. B 2009, 113, 15272-15277.

43. She, A.Q.; Gang, H.Z.; Mu, B.Z. Temperature influence on the structure and interfacial properties of surfactin micelle: A molecular dynamics simulation study. J. Phys. Chem. B 2012, 116, 12735-12743.

44. Osman, M.; Hoiland, H.; Holmsen, H. Micropolarity and microviscosity in the micelles of the heptapeptide biosurfactant "surfactin". Colloids Surf. B. Biointerfaces 1998, 11, 167-175. 
45. Bonmatin, J.-M.; Genest, M.; Labbé, H.; Ptak, M. Solution three-dimensional structure of surfactin: A cyclic lipopeptide studied by $1 \mathrm{H}-\mathrm{NMR}$, distance geometry, and molecular dynamics. Biopolymers 1994, 34, 975-986.

46. Tsan, P.; Volpon, L.; Besson, F.; Lancelin, J.-M. Structure and dynamics of surfactin studied by NMR in micellar media. J. Am. Chem. Soc. 2007, 129, 1968-1977.

47. Vass, E.; Besson, F.; Majer, Z.; Volpon, L.; Hollosi, M. $\mathrm{Ca}^{2+}$-induced changes of surfactin conformation: A FTIR and circular dichroism study. Biochem. Biophys. Res. Commun. 2001, 282, 361-367.

48. Shen, H.-H.; Thomas, R.K.; Chen, C.-Y.; Darton, R.C.; Baker, S.C.; Penfold, J. Aggregation of the naturally occurring lipopeptide, surfactin, at interfaces and in solution: An unusual type of surfactant? Langmuir 2009, 25, 4211-4218.

49. Grangemard, I.; Wallach, J.; Maget-Dana, R.; Peypoux, F. Lichenysin: A more efficient cation chelator than surfactin. Appl. Biochem. Biotechnol. 2001, 90, 199-210.

50. Razafindralambo, H.; Paquot, M.; Baniel, A.; Popineau, Y.; Hbid, C.; Jacques, P.; Thonart, P. Foaming properties of a natural cyclic lipoheptapeptide belonging to a special class of amphiphilic molecules. Food Hydrocolloids 1997, 11, 59-62.

51. Li, Y.; Zou, A.H.; Ye, R.Q.; Mu, B.Z. Effects of molecular structure on surfactin micellization activity. Acta Phys.-Chim. Sin. 2011, 27, 1128-1134.

52. Yakimov, M.M.; Fredrickson, H.L.; Timmis, K.N. Effect of heterogeneity of hydrophobic moieties on surface activity of lichenysin A, a lipopeptide biosurfactant from Bacillus licheniformis BAS50. Biotechnol. Appl. Biochem. 1996, 23, 13-18.

53. Dufour, S.; Deleu, M.; Nott, K.; Wathelet, B.; Thonart, P.; Paquot, M. Hemolytic activity of new linear surfactin analogs in relation to their physico-chemical properties. Biochim. Biophys. Acta 2005, 1726, 87-95.

54. Morikawa, M.; Hirata, Y.; Imanaka, T. A study on the structure-function relationship of lipopeptide biosurfactants. Biochim. Biophys. Acta 2000, 1488, 211-218.

55. Thimon, L.; Peypoux, F.; Das, B.C.; Wallach, J.; Michel, G. Selective esterification of surfactin: Preparation and properties of surfactin methyl esters. Biotechnol. Appl. Biochem. 1994, 20, 415-423.

56. Yakimov, M.M.; Timmis, K.N.; Wray, V.; Fredrickson, H.L. Characterization of a new lipopeptide surfactant produced by thermotolerant and halotolerant subsurface Bacillus licheniformis BAS50. Appl. Environ. Microbiol. 1995, 61, 1706-1713.

57. Grangemard, I.; Bonmatin, J.-M.; Bernillon, J.; Das, B.C.; Peypoux, F. Lichenysins G, a novel family of lipopeptide biosurfactants from Bacillus licheniformis IM 1307: Production, isolation and structural evaluation by NMR and mass spectrometry. J. Antibiot. 1999, 52, 363-373.

58. Bonmatin, J.-M.; Labbé, H.; Grangemard, I.; Peypoux, F.; Maget-Dana, R.; Ptak, M.; Michel, G. Production, isolation and characterization of [Leu4]- and [Ile4]surfactins from Bacillus subtilis. Lett. Pept. Sci. 1995, 2, 41-47.

59. Peypoux, F.; Bonmatin, J.M.; Labbe, H.; Grangemard, I.; Das, B.C.; Ptak, M.; Wallach, J.; Michel, G. [Ala4] surfactin, a novel isoform from Bacillus subtilis studied by mass and NMR spectroscopies. Eur. J. Biochem. 1994, 224, 89-96. 
60. Khire, J.M. Bacterial Biosurfactants, and Their Role in Microbial Enhanced Oil Recovery (MEOR). In Biosurfactants; Sen, R., Ed.; Springer New York: New York, NY, USA, 2010; Volume 672; pp. 146-157.

61. Sarafzadeh, P.; Hezave, A.Z.; Ravanbakhsh, M.; Niazi, A.; Ayatollahi, S. Enterobacter cloacae as biosurfactant producing bacterium: Differentiating its effects on interfacial tension and wettability alteration mechanisms for oil recovery during MEOR process. Colloids Surf. B. Biointerfaces 2013, $105,223-229$.

62. Al-Sulaimani, H.; Al-Wahaibi, Y.; Al-Bahry, S.; Elshafie, A.; Al-Bemani, A.; Joshi, S.; Ayatollahi, S. Residual-oil recovery through injection of biosurfactant chemical surfactant, and mixtures of both under reservoir temperatures: Induced-wettability and interfacial-tension effects. Spe Reserv. Eval. Eng. 2012, 15, 210-217.

63. Fiechter, A. Biosurfactants: Moving towards industrial application. Trends Biotechnol. 1992, 10, 208-217.

64. Kowalewski, E.; Rueslatten, I.; Steen, K.H.; Bodtker, G.; Torsaeter, O. Microbial improved oil recovery-Bacterial induced wettability and interfacial tension effects on oil production. J. Pet. Sci. Eng. 2006, 52, 275-286.

65. Crescente, C.; Rasmussen, K.; Torsæter, O.; Strøm, A.; Kowalewski, E. An Experimental Study of Bacterial Improved Oil Recovery by using Rhodococcus sp.094. Presented at International Symposium of the Society of Core Analysts, Toronto, Canada, 21-25 Auguest, 2005.

66. Banat, I.M.; Franzetti, A.; Gandolfi, I.; Bestetti, G.; Martinotti, M.G.; Fracchia, L.; Smyth, T.J.; Marchant, R. Microbial biosurfactants production, applications and future potential. Appl. Microbiol. Biotechnol. 2010, 87, 427-444.

67. Al-Wahaibi, Y.; Joshi, S.; Al-Bahry, S.; Elshafie, A.; Al-Bemani, A.; Shibulal, B. Biosurfactant production by Bacillus subtilis B30 and its application in enhancing oil recovery. Colloids Surf. B Biointerfaces 2014, 114, 324-333.

68. Schaller, K.D.; Fox, S.; Bruhn, D.; Noah, K.; Bala, G. Characterization of surfactin from Bacillus subtilis for application as an agent for enhanced oil recovery. Appl. Biochem. Biotechnol. 2004, 115, 827-836.

69. Makkar, R.S.; Cameotra, S.S. Structural characterization of a biosurfactant produced by Bacillus subtilis at $45^{\circ}$ C. J. Surfactants Deterg. 1999, 2, 367-372.

70. Youssef, N.; Simpson, D.R.; Duncan, K.E.; McInerney, M.J.; Folmsbee, M.; Fincher, T.; Knapp, R.M. In situ biosurfactant production by Bacillus strains injected into a limestone petroleum reservoir. Appl. Environ. Microbiol. 2007, 73, 1239-1247.

71. Youssef, N.; Simpson, D.R.; McInerney, M.J.; Duncan, K.E. In-situ lipopeptide biosurfactant production by Bacillus strains correlates with improved oil recovery in two oil wells approaching their economic limit of production. Int. Biodeterior. Biodegrad. 2013, 81, 127-132.

72. Gao, C.H.; Zekri, A. Applications of microbial-enhanced oil recovery technology in the past decade. Energy Sources Part A-Recovery Util. Environ. Eff. 2011, 33, 972-989.

73. Maudgalya, S.; Knapp, R.; McInerney, M. Microbial Enhanced Oil-Recovery Technologies: A review of the Past, Present, and Future. Presented at Production and Operations Symposium, Oklahoma City, OK, USA, 31 March-3 April, 2007. 
74. Weidong, W.; Junzhang, L.; Xueli, G.; Jing, W.; Ximing, L.; Yan, J.; Fengmin, Z. MEOR field test at block Luo801 of Shengli oil field in China. Pet. Sci. Technol. 2014, 32, 673-679.

75. Tuleva, B.K.; Ivanov, G.R.; Christova, N.E. Biosurfactant production by a new Pseudomonas putida strain. Z. Naturforsch. C 2002, 57, 356-360.

76. Pruthi, V.; Cameotra, S.S. Short communication: Production and properties of a biosurfactant synthesized by Arthrobacter protophormiae: An antarctic strain. World J. Microbiol. Biotechnol. 1997, 13, 137-139.

77. Maier, R.M.; Soberon-Chavez, G. Pseudomonas aeruginosa rhamnolipids: Biosynthesis and potential applications. Appl. Microbiol. Biotechnol. 2000, 54, 625-633.

78. Jenny, K.; Kappeli, O.; Fiechter, A. Biosurfactants from Bacillus licheniformis: Structural analysis and characterization. Appl. Microbiol. Biotechnol. 1991, 36, 5-13.

79. Cavalcante Barros, F.F.; de Quadrosi, C.P.; Pastore, G.M. Studies of emulsifying properties and stability of the biosurfactant produced by Bacillus subtilis in cassava wastewater. Cienc. Tecnol Aliment. 2008, 28, 979-985.

80. Kim, J. Isolation and characterization of a biosurfactant-producing bacterium Bacillus pumilus IJ-1 from contaminated crude oil collected in Taean, Korea. J. Korean Soc. Appl. Biol. Chem. 2014, 57, 5-14.

81. Saeki, H.; Sasaki, M.; Komatsu, K.; Miura, A.; Matsuda, H. Oil spill remediation by using the remediation agent JE1058BS that contains a biosurfactant produced by Gordonia sp strain JE-1058. Bioresour. Technol. 2009, 100, 572-577.

82. Crescenzi, F.; Buffagni, M.; D'Angeli, E.; Porcelli, F. A new biosurfactant for use in the clean up of oil spills on sea water environment. In Oil and Hydrocarbon Spills III: Modelling, Analysis and Control; Brebbia, C.A., Ed.; Wit Press: Southampton, UK, 2002; Volume 11, pp. 245-251.

83. Pavitran, S.; Jagtap, C.B.; Subramanian, S.B.; Titus, S.; Kumar, P.; Deb, P.C. Microbial bioremediation of fuel oil hydrocarbons in marine environment. Def. Sci. J. 2006, 56, 209-224.

84. Head, I.M.; Jones, D.M.; Roling, W.F.M. Marine microorganisms make a meal of oil. Nat. Rev. Micro 2006, 4, 173-182.

85. Harayama, S.; Kasai, Y.; Hara, A. Microbial communities in oil-contaminated seawater. Curr. Opin. Biotechnol. 2004, 15, 205-214

86. Yakimov, M.M.; Timmis, K.N.; Golyshin, P.N. Obligate oil-degrading marine bacteria. Curr. Opin. Biotechnol. 2007, 18, 257-266.

87. Banat, I.M. Potentials for use of biosurfactants in oil spills cleanup and oil bioremediation. In Oil and Hydrocarbon Spills, Modelling, Analysis and Control II; Rodriguez, G.R., Brebbia, C.A., Eds.; Wit Press: Southampton, UK, 2000; Volume 8, pp. 177-185.

88. Chhatre, S.; Purohit, H.; Shanker, R.; Khanna, P. Bacterial consortia for crude oil spill remediation. Water Sci. Technol. 1996, 34, 187-193.

89. Das, K.; Mukherjee, A.K. Crude petroleum-oil biodegradation efficiency of Bacillus subtilis and Pseudomonas aeruginosa strains isolated from a petroleum-oil contaminated soil from North-East India. Bioresour. Technol. 2007, 98, 1339-1345.

90. Pelletier, E.; Delille, D.; Delille, B. Crude oil bioremediation in sub-antarctic intertidal sediments: Chemistry and toxicity of oiled residues. Mar. Environ. Res. 2004, 57, 311-327. 
91. Harvey, S.; Elashvili, I.; Valdes, J.J.; Kamely, D.; Chakrabarty, A.M. Enhanced removal of exxon valdez spilled oil from alaskan gravel by a microbial surfactant. Nat. Biotechnol. 1990, 8, 228-230.

92. Swannell, R.P.; Lee, K.; McDonagh, M. Field evaluations of marine oil spill bioremediation. Microbiol. Rev. 1996, 60, 342-365.

93. Marti, M.E.; Colonna, W.J.; Patra, P.; Zhang, H.; Green, C.; Reznik, G.; Pynn, M.; Jarrell, K.; Nyman, J.A.; Somasundaran, P.; et al. Production and characterization of microbial biosurfactants for potential use in oil-spill remediation. Enzym. Microb. Technol. 2014, 55, 31-39.

94. Asaka, O.; Shoda, M. Biocontrol of Rhizoctonia solani damping-off of tomato with Bacillus subtilis RB14. Appl. Environ. Microbiol. 1996, 62, 4081-4085.

95. Joshi, S.; Bharucha, C.; Desai, A.J. Production of biosurfactant and antifungal compound by fermented food isolate Bacillus subtilis 20B. Bioresour. Technol. 2008, 99, 4603-4608.

96. Tendulkar, S.R.; Saikumari, Y.K.; Patel, V.; Raghotama, S.; Munshi, T.K.; Balaram, P.; Chattoo, B.B. Isolation, purification and characterization of an antifungal molecule produced by Bacillus licheniformis BC98, and its effect on phytopathogen magnaporthe grisea. J. Appl. Microbiol. 2007, 103, 2331-2339.

97. Bechard, J.; Eastwell, K.C.; Sholberg; Mazza, G.; Skura, B. Isolation and partial chemical characterization of an antimicrobial peptide produced by a strain of Bacillus subtilis. J. Agric. Food Chem. 1998, 46, 5355-5361.

98. Brötz, H.; Sahl, H.-G. New insights into the mechanism of action of lantibiotics-diverse biological effects by binding to the same molecular target. J. Antimicrob. Chemother. 2000, 46, 1-6.

99. Heerklotz, H.; Seelig, J. Leakage and lysis of lipid membranes induced by the lipopeptide surfactin. Eur. Biophys. J. 2007, 36, 305-314.

100. Carrillo, C.; Teruel, J.A.; Aranda, F.J.; Ortiz, A. Molecular mechanism of membrane permeabilization by the peptide antibiotic surfactin. Biochim. Biophys. Acta 2003, 1611, 91-97.

101. Fernandez-Lopez, S.; Kim, H.-S.; Choi, E.C.; Delgado, M.; Granja, J.R.; Khasanov, A.; Kraehenbuehl, K.; Long, G.; Weinberger, D.A.; Wilcoxen, K.M.; et al. Antibacterial agents based on the cyclic D,L- $\alpha$-peptide architecture. Nature 2001, 412, 452-455.

102. Brown, M.J. Biosurfactants for cosmetic applications. Int. J. Cosmet. Sci. 1991, 13, 61-64.

103. Nitschke, M.; Costa, S.G.V.A.O. Biosurfactants in food industry. Trends Food Sci. Technol. 2007, 18, 252-259.

104. Mulligan, C.N. Environmental applications for biosurfactants. Environ. Pollut. 2005, 133, 183-198.

105. Mulligan, C.N.; Yong, R.N.; Gibbs, B.F.; James, S.; Bennett, H.P.J. Metal removal from contaminated soil and sediments by the biosurfactant surfactin. Environ. Sci. Technol. 1999, 33, 3812-3820.

106. Zouboulis, A.I.; Matis, K.A.; Lazaridis, N.K.; Golyshin, P.N. The use of biosurfactants in flotation: Application for the removal of metal ions. Miner. Eng. 2003, 16, 1231-1236.

107. Iwamoto, T.; Fujie, A.; Sakamoto, K.; Tsurumi, Y.; Shigematsu, N.; Yamashita, M.; Hashimoto, S.; Okuhara, M.; Kohsaka, M. WF11899A, B and C, novel antifungal lipopeptides: I. Taxonomy, fermentation, isolation and physico-chemical properties. J. Antibiot. 1994, 47, 1084-1091. 
108. Nielsen, T.H.; Thrane, C.; Christophersen, C.; Anthoni, U.; Sorensen, J. Structure, production characteristics and fungal antagonism of tensin-A new antifungal cyclic lipopeptide from Pseudomonas fluorescens strain 96.578. J. Appl. Microbiol. 2000, 89, 992-1001.

109. Kim, P.I.; Bai, H.; Bai, D.; Chae, H.; Chung, S.; Kim, Y.; Park, R.; Chi, Y.T. Purification and characterization of a lipopeptide produced by Bacillus thuringiensis CMB26. J. Appl. Microbiol. 2004, 97, 942-949.

(C) 2015 by the authors; licensee MDPI, Basel, Switzerland. This article is an open access article distributed under the terms and conditions of the Creative Commons Attribution license (http://creativecommons.org/licenses/by/4.0/). 